\title{
Review of cost-effectiveness of antithrombotic alternatives in patients with atrial fibrillation
}

\author{
João Cruz Neto ${ }^{1 *}$ (1), Liana de Oliveira Barros² (1), \\ Sonia Samara Fonseca de Morais ${ }^{2}$ (D), Marcelo Gurgel Carlos da Silva ${ }^{2}$
}

\section{INTRODUCTION}

A cerebrovascular accident is a pathological entity with the vascular impairment of sudden onset, which leads to the lowering of the level of consciousness, differentiating it into ischemic or hemorrhagic, with emphasis on cases related to atrial fibrillation $(\mathrm{AF})^{1,2}$.

Stroke is one of the main reasons for the use of public health resources, both in the inhospital and outpatient phases of the disease. Its expenses may be associated with the loss of early economic productivity, the development of psychological damage, the decrease in social interaction, and the loss of quality of life for the individual and their family ${ }^{3,4}$.

It is estimated that Brazil has more than 2 million people over 18 years of age who have a stroke, with a higher prevalence in older adults 5 . Stroke is the second leading cause of death worldwide and the main cause of disability after a traumatic event. It is among the main problems in hospital urgencies and emergencies, representing 5.7 of a total of 58 million global deaths ${ }^{6}$.

It is estimated that the mean hospitalization cost per type of stroke in Brazilian services is US $\$ 3,827$ per year and increases to US\$9,505 in those patients with AF, while in countries such as the United States, it exceeds US $\$ 40,743$ if intravenous thrombolysis is associated ${ }^{7,8}$.

The prevention of stroke and its complications by the administration of anticoagulants is one of the main objectives of the treatment for this pubic ${ }^{9}$. Most of the costs for stroke treatment are incurred in the first year after the injury, incurred by the highly complex procedures performed in this period ${ }^{7}$.

Currently, the therapeutic strategies available on a larger scale are vitamin $\mathrm{K}$ antagonists, such as warfarin, which reduce the risk of stroke complications by up to $64 \%$.
This study analyzes the evidence on the cost-effectiveness of antithrombotic alternatives in patients with $\mathrm{AF}$ as stroke prevention.

\section{METHODS}

This study comprises an integrative literature review. The research took place from August to September 2019 with the following steps:

1. The identification of the topic and selection of the research question using the Population (inpatients), Intervention (cost and cost analysis), Comparison (not applicable to the study), and Outcome (stroke, critical care, and AF) strategy. The research question was as follows: what is the scientific evidence on the cost-effectiveness of antithrombotic alternatives in patients with $\mathrm{AF}$ as stroke prevention?

2. The establishment of the inclusion and exclusion criteria: articles available electronically; originals; patients older than 18 years of age; studies published in Portuguese, English, or Spanish; and met the cost-effectiveness analysis method. There was no time limit. Those that did not address the investigated theme were excluded.

3. The establishment of a search strategy: Nursing Database (Base de dados em Enfermagem), Latin American and Caribbean Literature on Health Sciences database, Medical Literature Analysis and Retrieval System Online database, SCOPUS Preview, and Cumulative Index to Nursing and Allied Health Literature. In each database, the subject descriptors in the Medical Subject Heading of PubMed were delimited and crossed, and the following were used: Inpatients, Stroke, Critical Care,

\footnotetext{
'Universidade Regional do Cariri, Departamento de Enfermagem - Crato (CE), Brazil.

¿2Universidade Estadual do Ceará, Programa de Pós Graduação em Saúde Coletiva - Fortaleza (CE), Brazil.

*Corresponding author: enfjcncruz@gmail.com

Conflicts of interest: the authors declare there is no conflicts of interest. Funding: none.

Received on March 23, 2021. Accepted on June 06, 2021.
} 
and Costs and cost analysis and their Descritores em Ciências da Saúde, with the Boolean operators AND and OR, in a paired manner by two different researchers. Titles were assessed, followed by abstracts and finally the full texts according to the exclusion and inclusion criteria established.

4. The presentation of the search and selection of data from the Preferred Reporting Items for Systematic Review and Meta-Analyses review protocol (Figure 1).

5. The evaluation and synthesis of studies: studies were evaluated according to the seven levels of evidence ${ }^{10}$. The data are presented in tables and narratives.

\section{RESULTS}

This review included 18 articles (Table 1$)^{11-28}$ assessed according to authors, year of publication, study design, country of publication, therapeutic alternatives versus cost, and principal conclusions. In the cost analysis, the main currencies of circulation were the euro ${ }^{11-13,19-23}$ and the dollar ${ }^{14-18,20-22,24,25}$.

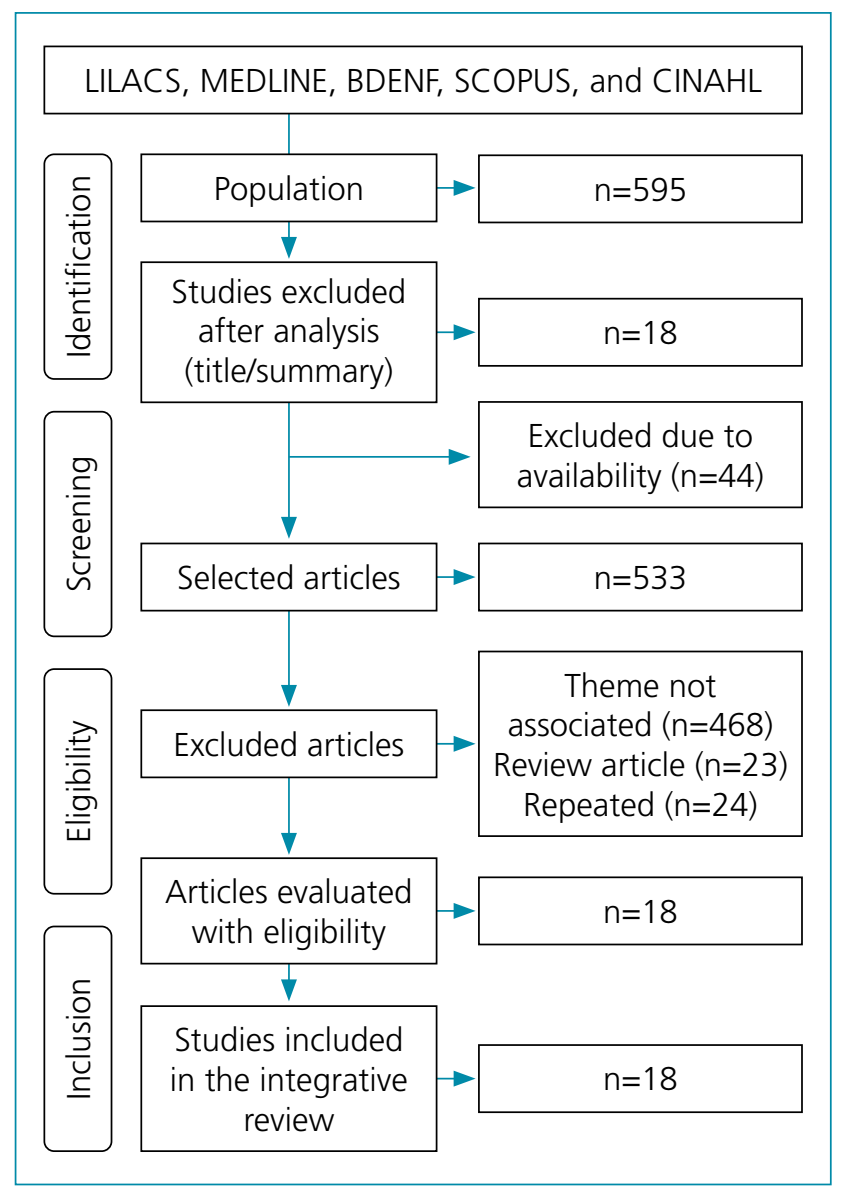

Figure 1. Flowchart of the article search and selection process, Brazil, in 2020.
The best quality-adjusted life years (QALYs) were conferred by the following: dabigatran, apixaban, warfarin, rivaroxaban, and edoxaban.

Apixaban effectively reduces the number of cardiovascular events in relation to the vitamin $\mathrm{K}$ analogs apixaban and warfarin. It may be the first-line treatment for stroke prevention in patients with $\mathrm{AF}^{11}$ and is cost-effective ${ }^{17}$. Dabigatran was more cost-effective than rivaroxaban and warfarin for patients with AF, besides reducing the risk of stroke, pulmonary embolism, and intracranial hemorrhage with low bleeding ${ }^{12,14-20}$.

\section{DISCUSSION}

It is known that $\mathrm{AF}$ is a cardiac abnormality characterized by the total disorganization of atrial electrical activity ${ }^{29}$ and that stroke is one of the main complication $s^{30}$. Therapy with oral anticoagulants plays a key role in the treatment of AF, avoiding the risk of thromboembolic stroke, although this therapy may bring some risk of intracerebral hemorrhage ${ }^{31}$.

The highest costs of stroke in healthcare systems are incurred by patients with AF, causing a burden of more than US $\$ 1.5$ million $^{32}$ due to the multi-professional care required by these patients.

The economic impact caused by stroke is great, especially when associated with patients with $\mathrm{AF}^{33}$, and therapeutic choices should be precise to minimize the associated costs. Thus, anticoagulant therapy is the most effective alternative for the prevention and treatment of thromboembolic diseases ${ }^{9,34}$. Therefore, it is relevant to discuss the costs related to the effectiveness of the therapeutic options found in the market.

It was observed that the Markov model had more acceptances in the analyzed studies. This model is used for economic evaluations in healthcare systems, considering the evaluation of costs and clinical outcomes, especially in evaluating chronic diseases $^{35}$, which justifies its use in most of the studies included here.

Hospital services are overloaded with the demand from stroke centers, with an average of 10 patients/day'. This leads to the construction of research directed at pharmacological therapy with the best evidence of cost-effectiveness. A study on patients with ischemic and hemorrhagic stroke sequelae showed that the severity of symptoms was greater in those with AF, which is the group with significant expenses 8 .

Dabigatran is associated with significantly fewer hospitalizations in patients with AF than warfarin, and there was no significant difference in the mean cost of expenses between the two $\operatorname{drugs}^{36}$. This corroborates the data obtained here regarding the decrease in total expenses by the addition of dabigatran therapy.

Dabigatran is also indicated with a decrease of US\$2,119,252,605 in 3 years in patients with nonvalvular 
Table 1. Characterization of the articles included in the review regarding the research components, Brazil, in 2020.

$\begin{aligned} & \text { Author/year/drawing/country/leve } \\ & \text { of evidence }\end{aligned}$
Athanasakis et al. ${ }^{11}, 2017$
Cost-effectiveness analysis with
adapted Markov model/Cohort with
1,000 patients/Greece/lV

1,000 patic

\section{Alternative/monetary cost for better QALYs*}

Apixaban/warfarin $(€ 3,210.11)$ and VKA analogs $(€ 2,019.29)$

\section{Main conclusions}

Apixaban is predictive in reducing the number of cardiovascular events compared with the vitamin $\mathrm{K}$ analogs apixaban and warfarin. Apixaban may be the first-line choice in stroke prevention treatment in patients with AF. It reduces mortality and morbidity and provides health system resolutions for populations with multiple comorbidities.

Shah et al. ${ }^{12}, 2016$

Cost-effectiveness analysis with Markov model/Cohort with 10,000 patients/ United States/IV

Dabigatran, rivaroxaban, apixaban, and edoxaban in the comparison between apixaban and warfarin $(€ 25,816)$ and between $\mathrm{ACO}$ and warfarin $(€ 100,000)$

Esquivias et al. ${ }^{13}, 2014$ Cost-effectiveness analysis with the model adapted from Dorian/Cohort with 1,000 patients/Spain/IV

Peng et al. ${ }^{14}, 2017$

Markov model health cost-effectiveness panel/Cohort with 10,000 patients/ United States/IV

Lee et al. ${ }^{15}, 2016$

Cost-effectiveness analysis with Markov model/Cohort/China/IV
Dabigatran/dabigatran

(US\$3,343) rivaroxaban (US\$3,339)
Apixaban $(€ 30,000)$

Apixaban (US\$53,315), rivaroxaban (US\$51,064), dabigatran $150 \mathrm{mg}$ (US\$43,946), dabigatran $110 \mathrm{mg}$ (US\$42,712), LAAO

(US\$37,789), warfarin
Oral anticoagulants (ACO) are the most effective alternative when the dose of warfarin is adjusted. Apixaban has high QALYs in AF patients. Dabigatran has higher QALYs for stroke risk. The QALYs of ACO have costeffectiveness sensitive to the main drugs.

Apixaban is cost-effective in preventing stroke in patients with nonvalvular AF compared with acenocoumarol by $87 \%$.

Dabigatran is more cost-effective than rivaroxaban for patients with AF. Dabigatran further reduces the risk for stroke and pulmonary embolism with low bleeding and interdrug costs. (US\$28,090), clopidogrel plus AAS (US $\$ 26,287)$, AAS (US\$12,777)

Lee et al. ${ }^{16}, 2012$ Incremental cost-effectiveness with the Markov model/Randomized controlled trial/United States/II

Apixaban/apixaban (US\$44,232) and aspirin (US\$50,066).

Apixaban, dabigatran, rivaroxaban/compared warfarin with apixaban, apixaban (US\$7,513) was more cost effective.

Dabigatran/dabigatran (US\$1,061) and warfarin (US\$1,306) Belgium/IV
Cost-effectiveness analysis/Cohort with 244 patients/China/IV

Wouters et al. ${ }^{19}, 2013$

Cost-effectiveness analysis with Markov model/Cohort with 10,000 patients/

Harrington et al. ${ }^{17}, 2013$

Cost-effectiveness analysis with Markov model/Cohort/United States/IV

Chang et al. ${ }^{18}, 2013$

v

\section{Dabigatran/dabigatran}

$(€ 2,807)$ and warfarin $(€ 20,000)$
LAAO§ is cost-effective compared with apixaban, rivaroxaban, dabigatran $150 \mathrm{mg}$, dabigatran $110 \mathrm{mg}$, warfarin, clopidogrel plus, and AAS in the prevention of stroke with nonvalvular AF.
Apixaban is more effective than aspirin; over time, it has become cost-effective and economically dominant.
Apixaban is cost-effective in treatment with thresholds >US\$40,000 per QALY. Warfarin is the most cost-effective $A C$ in the treatment of patients with AF as prophylactic prevention of stroke.

Dabigatran was cost-effective compared with warfarin, and the drug can be used for stroke prevention in patients with AF.

Dabigatran is the most cost-effective treatment for stroke prevention in patients with $A F$, representing good monetary value for healthcare settings. 
Table 1. Continuation.

\begin{tabular}{|c|c|c|}
\hline $\begin{array}{l}\text { Author/year/drawing/country/level } \\
\text { of evidence }\end{array}$ & $\begin{array}{l}\text { Alternative/monetary } \\
\text { cost for better QALYs* }\end{array}$ & Main conclusions \\
\hline $\begin{array}{l}\text { Kansal et al. }{ }^{20}, 2012 \\
\text { Cost-effectiveness analysis with Markov } \\
\text { model/Cohort with } 100 \text { patients/ } \\
\text { England/IV }\end{array}$ & $\begin{array}{l}\text { Dabigatran and warfarin/ } \\
\text { dabigatran }(€ 10,424) \text { and } \\
\quad \text { warfarin }(€ 9,919)\end{array}$ & $\begin{array}{l}\text { Dabigatran treatment reduces the risk of } \\
\text { stroke and intracranial hemorrhage compared } \\
\text { with warfarin. Dabigatran is the cost-effective } \\
\text { first-line alternative for patients with AF and } \\
\text { decreases the risk of stroke. }\end{array}$ \\
\hline $\begin{array}{l}\text { Coyle et al. }{ }^{21}, 2013 \\
\text { Cost-effectiveness analysis with the } \\
\text { Markov model/Cohort/Canada/IV }\end{array}$ & $\begin{array}{c}\text { Apixaban }(€ 11,742) \text {, } \\
\text { dabigatran }(€ 50,000) \text {, } \\
\text { warfarin and rivaroxaban }\end{array}$ & $\begin{array}{c}\text { Rivaroxaban and dabigatran } 110 \text { mg are cost- } \\
\text { effective, with dabigatran having less impact } \\
\text { on bleeding. }\end{array}$ \\
\hline $\begin{array}{l}\text { Morais et al. }{ }^{22}, 2014 \\
\text { Cost-effectiveness analysis with the } \\
\text { Markov model/Nonrandomized study/ } \\
\text { Portugal//II }\end{array}$ & $\begin{array}{l}\text { Rivaroxaban }(€ 3,895) \\
\quad \text { warfarin }(€ 3,494)\end{array}$ & $\begin{array}{c}\text { Rivaroxaban showed greater cost-effectiveness } \\
\text { than vitamin } \mathrm{K} \text { analogs and is the indicated } \\
\text { therapy for stroke prophylaxis in patients with } \\
\text { AF. }\end{array}$ \\
\hline $\begin{array}{l}\text { Stevanovic et al. }{ }^{23}, 2014 \\
\text { Using efficacy by ARISTOTLE and } \\
\text { AVERROES Markov Model/Cohort with } \\
\text { 1,000 patients/Netherlands/IV }\end{array}$ & $\begin{array}{c}\text { Apixaban }(€ 14,113) \text { and } \\
\text { VKA }(€ 14,904)\end{array}$ & $\begin{array}{l}\text { Apixaban is the most cost-effective alternative } \\
\text { and has high treatment importance. However, } \\
\text { due to the effects, it will be the second choice } \\
\text { of treatment. }\end{array}$ \\
\hline $\begin{array}{l}\text { Reddy et al. }{ }^{24}, 2015 \\
\text { Cost-effectiveness analysis with the } \\
\text { Markov model/Nonrandomized study/ } \\
\text { United States/III }\end{array}$ & $\begin{array}{l}\text { Right atrial appendage } \\
\text { closure (U\$20,892) and } \\
\text { ACO (US\$20,924) }\end{array}$ & $\begin{array}{c}\text { Appendix closure and OAC are cost-effective } \\
\text { alternatives to stroke prevention in patients } \\
\text { with AF }\end{array}$ \\
\hline $\begin{array}{l}\text { Ali et al. }{ }^{25}, 2012 \\
\text { Prospective observational study with } \\
402 \text { patients/United States } N\end{array}$ & $\begin{array}{c}\text { The cost of warfarin } \\
\text { (US } \$ 2,073) \text { and dabigatran } \\
\text { (US } \$ 17,535)\end{array}$ & $\begin{array}{l}\text { Warfarin becomes more cost-effective for } \\
\text { patients with AF in stroke prevention because } \\
\text { dabigatran has the highest price. }\end{array}$ \\
\hline $\begin{array}{l}\text { Miguel et al. }{ }^{26}, 2013 \\
\text { Cost-effectiveness analysis with the } \\
\text { Markov model/Nonrandomized study } \\
\text { with } 117 \text { patients/Portugal/III }\end{array}$ & $\begin{array}{l}\text { Dabigatran/dabigatran } \\
(€ 8,409)\end{array}$ & $\begin{array}{l}\text { Dabigatran reduces the risk of ischemic } \\
\text { and hemorrhagic stroke and intracranial } \\
\text { hemorrhage. It is shown to be cost-effective by } \\
\text { waiving the international standardization rate. }\end{array}$ \\
\hline $\begin{array}{l}\text { Miguel and Ferreira }{ }^{27}, 2016 \\
\text { Cost-effectiveness analysis with the } \\
\text { Markov model/Comparative study } \\
\text { RE-LY and ROCKET AF with 71.693/ } \\
\text { Portugal/IV }\end{array}$ & $\begin{array}{c}\text { Dabigatran and } \\
\text { rivaroxaban/dabigatran } \\
(€ 11,858) \text { and rivaroxaban } \\
(€ 12,223)\end{array}$ & $\begin{array}{l}\text { Dabigatran, in patients with } A F \text {, provides better } \\
\text { clinical results than rivaroxaban in the same } \\
\text { indication. }\end{array}$ \\
\hline $\begin{array}{l}\text { Magnuson et al. }{ }^{28}, 2015 \\
\text { Cost-effectiveness analysis with Markov } \\
\text { model and ENGAGE AF-TIMI } 48 \text { with } \\
21.105 / \text { Cohort study/United States/IV }\end{array}$ & $\begin{array}{l}\text { Edoxaban and warfarin/ } \\
\text { edoxaban }(€ 43,370) \text { and } \\
\text { warfarin }(€ 26,986)\end{array}$ & $\begin{array}{c}\text { Edoxaban becomes the most cost-effective } \\
\text { alternative due to its wide sensitivity with } \\
\text { impacts on post-stroke quality of life and } \\
\text { bleeding. }\end{array}$ \\
\hline
\end{tabular}

QALY: quality-adjusted life-year; VKA: vitamin K antagonist; AF: atrial fibrillation; ACO: oral anticoagulant; LAAO: right atrial appendage transcatheter; AAS: acetylsalicylic acid; Monetary values were taxed according to the currency of each country at the time of the research.

AF in Colombia, being a viable alternative compared with apixaban, rivaroxaban, and warfarin in the medium term ${ }^{37}$. In this study, the increase was more than US $\$ 2,000$, reinforcing that in years of gains, this therapeutic alternative exceeds the expectations of the payer, such as the public system, and improves the quality of life of the population that uses the drug.

Dabigatran and rivaroxaban have low medical costs for preventing stroke in people with $\mathrm{AF}^{38}$. Other drugs are also noted for their cost-effectiveness. In this study, the new oral anticoagulants (dabigatran, $110 \mathrm{mg}$; apixaban and rivaroxaban, $150 \mathrm{mg}$ each) were found to be cost-effective compared with conventional strategies?.

\section{CONCLUSIONS}

Antithrombotic alternatives have been the target of international studies with the purpose of reducing public service costs and increasing patients' quality of life, considering alternatives 
that are more effective in patients with different pathologies and those with direct impacts on public spending.

Apixaban and dabigatran were shown to be cost-effective regarding the quality years of life gained; both can be used in patients with AF, including the critically ill, to prevent hematological disorders and cardiovascular events such as stroke.

Studies in this area enable the first-line treatment in disease prevention and significantly reduce public spending, taking into account the years of life gained, reducing mortality and inhospital morbidity. Research on this topic is also suggested in the Brazilian scenario to provide evidence for cost-effective alternatives with lower public service expenses.

\section{AUTHORS" CONTRIBUTIONS}

JCN: Conceptualization, Investigation, Writing - original draf. LOB: Data curation, Writing - original draf. SSFM: Visualization, Writing - review \& editing. MGCS: Supervision, Writing - review \& editing.

\section{REFERENCES}

1. Donkor ES. Stroke in the $21^{\text {st }}$ century: a snapshot of the burden, epidemiology, and quality of life. Stroke Res Treat. 2018;2018:3238165. https://doi.org/10.1155/2018/3238165

2. Mamed SN, Ramos AMO, Araújo VEM, Jesus WS, Ishitani $\mathrm{LH}$, França EB. Profile of deaths from unspecified stroke after investigation of garbage codes in 60 cities in Brazil, 2017. Rev Bras Epidemiol. 2019;22(Suppl 3):e190013.supl3. https://doi. org/10.1590/1980-549720190013.supl.3

3. Reis MF, Chaoubah A, Mármora CHC, Liebel G. Cost analysis of outpatient stroke in the public system perspective. J Bras Econ Saúde. 2018;10(3):219-25.

4. Tinoco CSL, Santos PMC. Anesthetic management of endovascular treatment for acute ischemic stroke: influences on outcome and complications. Braz J Anesthesiol. 2018;68(6):61323. https://doi.org/10.1016/j.bjan.2018.06.004

5. Bensenor IM, Goulart AC, Szwarcwald CL, Vieira MLFP, Malta DC, Lotufo PA. Prevalence of stroke and associated disability in Brazil: National Health Survey - 2013. Arq Neuropsiquiatr. 2015;73(9):746-50. https://doi.org/10.1590/0004282X20150115

6. Organização Pan-Americana da Saúde. Organização Mundial da Saúde. Search for 10 principais causas de morte no mundo Brasil. [cited on April 28, 2020]. Available from: https://www.paho.org/ bra/index.php?option=com_content $\&$ view=article\&id=5638:10principais-causas-de-morte-no-mundo\&ltemid=0.

7. Rai AT, Boo S, Buseman C, Adcock AK, Tarabishy AR, Miller $\mathrm{MM}$, et al. Intravenous thrombolysis before endovascular therapy for large vessel strokes can lead to significantly higher hospital costs without improving outcomes. J Neurointerv Surg. 2018;10(1):17-21. https://doi.org/10.1136/ neurintsurg-2016-012830

8. Vieira LGDR, Safanelli J, Araujo T, Schuch HA, Kuhlhoff MHR, Nagel $\mathrm{V}$, et al. The cost of stroke in private hospitals in Brazil: a one-year prospective study. Arq Neuropsiquiatr. 2019;77(6):393403. https://doi.org/10.1590/0004-282X20190056

9. Ferreira J, Mirco A. Systematic review of cost-effectiveness analyses of novel oral anticoagulants for stroke prevention in atrial fibrillation. Rev Port Cardiol. 2015;34(3):179-91. https:// doi.org/10.1016/j.repc.2014.08.008

10. Stilwell SB, Fineout-Overhalt E, Melnyk BM, Williamson KM. Evidence-based practice, step by step: searching for the evidence. Am J Nurs. 2010;110(5):41-7. https://doi. org/10.1097/01.NAJ.0000372071.24134.7e
11. Athanasakis K, Boubouchairopoulou N, Karampli E, Tarantilis F, Savvari P, Bilitou A, et al. Cost effectiveness of apixaban versus warfarin or aspirin for stroke prevention in patients with atrial fibrillation: a Greek perspective. Am J Cardiovasc Drugs. 2017;17(2):123-33. https://doi.org/10.1007/s40256016-0204-1

12. Shah A, Shewale A, Hayes CJ, Martin BC. Cost-effectiveness of oral anticoagulants for ischemic stroke prophylaxis among nonvalvular atrial fibrillation patients. Stroke. 2016;47(6):155561. https://doi.org/10.1161/STROKEAHA.115.012325

13. Esquivias GB, Albaladejo GE, Zamorano JL, Nicolás LB, Fontcuberta CC, Salas-Cansado M, et al. Cost-effectiveness analysis comparing apixaban and acenocoumarol in the prevention of stroke in patients with nonvalvular atrial fibrillation in Spain. Rev Esp Cardiol (Engl Ed). 2015;68(8):680-90. https:// doi.org/10.1016/j.rec.2014.08.010

14. Peng S, Deger KA, Ustyugova A, Gandhi P, Qiao N, Wang $C$, et al. Cost-effectiveness analysis of dabigatran versus rivaroxaban for stroke prevention in patients with non-valvular atrial fibrillation using real-world evidence in elderly US medicare beneficiaries. Curr Med Res Opin. 2018;34(1):55-63. https:// doi.org/10.1080/03007995.2017.1375470

15. Lee VWY, Tsai RBC, Chow IHI, Yan BPY, Kaya MG, Park JW, et al. Cost-effectiveness analysis of left atrial appendage occlusion compared with pharmacological strategies for stroke prevention in atrial fibrillation. BMC Cardiovasc Disord. 2016;16(1):167. https://doi.org/10.1186/s12872016-0351-y

16. Lee S, Anglade MW, Meng J, Hagstrom K, Kluger J, Coleman $\mathrm{Cl}$. Cost-effectiveness of apixaban compared with aspirin for stroke prevention in atrial fibrillation among patients unsuitable for warfarin. Circ Cardiovasc Qual Outcomes. 2012;5(4):472-9. https://doi.org/10.1161/CIRCOUTCOMES.112.965251

17. Harrington AR, Armstrong EP, Nolan Jr EP, Malone DC. Cost-effectiveness of apixaban, dabigatran, rivaroxaban, and warfarin for stroke prevention in atrial fibrillation. Stroke. 2013;44(6):1676-81. https://doi.org/10.1161/ STROKEAHA.111.000402

18. Chang AM, Ho JCS, Yan BP, Yu CM, Lam YY, Lee VWY. Costeffectiveness of dabigatran compared with warfarin for stroke prevention in patients with atrial fibrillation - a real patient data analysis in a Hong Kong teaching hospital. Clin Cardiol. 2013;36(5):280-5. https://doi.org/10.1002/clc.22112 
19. Wouters H, Thijs V, Anneman, L. Cost-effectiveness of dabigatran etexilate in the prevention of stroke and systemic embolism in patients with atrial fibrillation in Belgium. J Med Econ. 2013;16(3):407-14. https://doi.org/10.3111/1369699 8.2013.766200

20. Kansal AR, Sorensen SV, Gani R, Robinson P, Pan F, Plum $J M$, et al. Cost-effectiveness of dabigatran etexilate for the prevention of stroke and systemic embolism in UK patients with atrial fibrillation. Heart. 2012;98(7):573-8. https://doi. org/10.1136/heartjnl-2011-300646

21. Coyle D, Coyle K, Cameron C, Lee K, Kelly S, Steiner S, et al. Cost-effectiveness of new oral anticoagulants compared with warfarin in preventing stroke and other cardiovascular events in patients with atrial fibrillation. Value Health. 2013;16(4):498506. https://doi.org/10.1016/j.jval.2013.01.009

22. Morais J, Aguiar C, McLeod E, Chatzitheofilou I, Santos IF, Pereira S. Cost-effectiveness of rivaroxaban for stroke prevention in atrial fibrillation in the Portuguese setting. Rev Port Cardiol. 2014;33(9):535-44. https://doi.org/10.1016/j. repc.2014.02.020

23. Stevanovi区 J, Pompen M, Le HH, Rozenbaum MH, Tieleman RG, Postma MJ. Economic evaluation of apixaban for the prevention of stroke in non-valvular atrial fibrillation in the Netherlands. PLoS One. 2014;9(8):e103974. https://doi. org/10.1371/journal.pone.0103974

24. Reddy VY, Akehurst RL, Armstrong SO, Amorosi SL, Beard SM, Holmes Jr DR. Time to cost-effectiveness following stroke reduction strategies in AF: warfarin versus NOACs versus LAA closure. J Am Coll Cardiol. 2015;66(24):2728-39. https://doi. org/10.1016/j.jacc.2015.09.084

25. Ali A, Bailey $C$, Abdelhafiz AH. Stroke prophylaxis with warfarin or dabigatran for patients with non-valvular atrial fibrillationcost analysis. Age Ageing. 2012;41(5):681-4. https://doi. org/10.1093/ageing/afs017

26. Miguel LS, Rocha E, Ferreira J. Economic evaluation of dabigatran for stroke prevention in patients with non-valvular atrial fibrillation. Rev Port Cardiol. 2013;32(7-8):557-65. https:// doi.org/10.1016/j.repc.2013.01.005

27. Miguel LS, Ferreira J. Clinical and economic consequences of using dabigatran or rivaroxaban in patients with non-valvular atrial fibrillation. Rev Port Cardiol. 2016;35(3):141-8. https:// doi.org/10.1016/j.repc.2015.09.009

28. Magnuson EA, Vilain K, Wang K, Li H, Kwong WJ, Antman EM, et al. Cost-effectiveness of edoxaban vs warfarin in patients with atrial fibrillation based on results of the ENGAGE
AF-TIMI 48 trial. Am Heart J. 2015;170(6):1140-50. https:// doi.org/10.1016/j.ahj.2015.09.011

29. Longo DL, Fauci AS, Kasper DL, Hauser SL, Jameson JL, Loscalzo J. Harrison's principles of internal medicine. 18th ed. New York: McGraw Hill; 2012

30. Hobbs FR, Taylor CJ, Geersing GJ, Rutten FH, Brouwer JR. European Primary Care Cardiovascular Society (EPCCS) consensus guidance on stroke prevention in atrial fibrillation (SPAF) in primary care. Eur J Prev Cardiol. 2016;23(5):460-73. https://doi.org/10.1177/2047487315571890

31. Adam SS, McDuffie JR, Ortel TL, Williams Jr JW. Comparative effectiveness of warfarin and new oral anticoagulants for the management of atrial fibrillation and venous thromboembolism: a systematic review. Ann Intern Med. 2012;157(11):796-807. https://doi.org/10.7326/0003-4819-157-10-201211200-00532

32. Ali N, Howe J, Abdel-Hafiz A. Cost of acute stroke care for patients with atrial fibrillation compared with those in sinus rhythm. Pharmacoeconomics. 2015;33(5):511-20. https:// doi.org/10.1007/s40273-015-0263-1

33. Li X, Tse VC, Au-Doung LW, Wong ICK, Chan EW. The impact of ischaemic stroke on atrial fibrillation-related healthcare cost: a systematic review. Europace. 2017;19(6):937-47. https:// doi.org/10.1093/europace/euw093

34. Wan Z, Li C, Long F, Zhang Y, Wang B, Wu Y, et al. Costeffectiveness analysis of a standardized management program for ischemic stroke patients in Hainan Province, China. Popul Health Manag. 2018;21(3):253-4. https://doi.org/10.1089/ pop.2017.0205

35. Sato RC, Zouain DM. Markov models in health care. Einstein. 2010;8(3 Pt 1):376-9. https://doi.org/10.1590/S167945082010RB1567

36. Reynolds SL, Ghate SR, Sheer R, Gandhi PK, Moretz C, Wang $C$, et al. Healthcare utilization and costs for patients initiating dabigatran or warfarin. Health Qual Life Outcomes. 2017;15(1):128. https://doi.org/10.1186/s12955-017-0705-x

37. Lasalvia P, Hernández F, Castañeda C. Impacto presupuestal de dabigatrán en comparación con apixabán, rivaroxabán y warfarina para el tratamiento de fibrilación auricular no valvular en Colombia. Acta Neurol Colomb. 2018;34(3):169-74.

38. Amin A, Keshishian A, Vo L, Zhang Q, Dina O, Patel C, et al. Realworld comparison of all-cause hospitalizations, hospitalizations due to stroke and major bleeding, and costs for non-valvular atrial fibrillation patients prescribed oral anticoagulants in a US health plan. J Med Econ. 2017;21(3):244-53. https://doi. org/10.1080/13696998.2017.1394866 